\title{
NEUROLOGICAL, ELECTROENCEPHALOGRAPHIC, AND HEREDO-FAMILIAL ASPECTS OF PSEUDOHYPOPARATHYROIDISM AND PSEUDO-PSEUDOHYPOPARATHYROIDISM*
}

BY

\author{
L. G. DICKSON, Y. MORITA, E. J. COWSERT, J. GRAVES, and J. S. MEYER \\ From the Departments of Neurology and Medicine, Detroit Receiving Hospital, and the Department of \\ Neurology, Wayne State University College of Medicine.
}

The Neurology and Medical Departments of the Detroit Receiving Hospital have recently made clinical and electroencephalographic (E.E.G.) studies of two patients in a family in which several members appear to have either pseudohypoparathyroidism or pseudo-pseudohypoparathyroidism. The findings were of sufficient interest to prompt us to review this subject and to present our findings since the neurological, electroencephalographic, and hereditary features of these rare conditions have not been reported in detail (Sugar, 1953; Frame and Carter, 1955), and the family history suggests that pseudo-pseudohypoparathyroidism may represent a forme fruste of pseudohypoparathyroidism.

It is well known that disordered calcium and phosphorus metabolism may result in neurological and E.E.G. abnormality and only a brief summary of the physiology of the parathyroid glands together with a description of pseudohypoparathyroidism and pseudo-pseudohypoparathyroidism will be given.

The function of the parathyroid glands is to regulate calcium, phosphorus, and bone metabolism through the action of their hormone on the renal tubule and bone. Parathyroid hormone decreases tubular phosphorus reabsorption, increases urinary phosphorus, and thus decreases serum phosphorus. As a result, there are increased levels of calcium in the serum and urine. Such changes are due, not only to the action of parathyroid hormone on the renal tubules alone, but also to a direct action of the hormone on the matrix of bone facilitating the mobilization of calcium and phosphorus (Carnes, 1950; Stewart and Bowen, 1951; Milne, 1951).

Pseudohypoparathyroidism was first described by Albright, Burnett, Smith, and Parson (1942). In this condition, there is hyperphosphataemia and hypocalcaemia similar to true hypoparathyroidism;

*This work was supported by U.S.P.H.S. Research Grant No. B-1645, 1958-1959 and by a grant from the Michigan Epilepsy Center. however, parathyroid biopsy reveals normal or hyperplastic glands and administration of parathyroid hormone does not cause significant phosphaturia or increase in serum calcium. This is the test described by Ellsworth and Howard in 1934. In this disease, neutralizing antibodies to parathyroid hormone have not been found in the patients' sera, with the single exception of the case reported by Harell-Steinberg, Ziprkowski, Haim, Gafni, and Levin (1957) which presented as hypoparathyroidism.

Decreased serum calcium in pseudohypoparathyroidism results in excessive neuromuscular irritability by facilitating the transmission of impulses across the myoneural junction. In addition, there is increased neuronal excitability resulting in seizures and abnormalities of the E.E.G. In several, the reported E.E.G. abnormalities consist of paucity of alpha rhythm, increased fast activity, sporadic spike activity, and slow waves (6-7 per second) with frontal preponderance (Frame and Carter, 1955; Sugar, 1953).

About two-thirds of patients with pseudohypoparathyroidism present with complaints of tetany. Usually there is carpopedal spasm with flexion of stiff, rigid fingers at the metacarpal-phalangeal joints, a stiff cupped palm, flexion of the wrist, and extension of the hip and knee joints. In addition, there may be tonic and clonic convulsions, laryngeal stridor (which may be fatal), paresthesiae, muscle cramps, and weakness. The pharyngeal weakness may result in dysphagia and dysarthria. Spasm of smooth muscle occurs throughout the body resulting in mydriasis, abdominal cramps, urinary frequency, tenesmus, and generalized arterial and arteriolar constriction. Fatigue, muscle weakness, palpitation, and tingling of the extremities are frequent complaints. Hypocalcaemia is occasionally associated with cardiac irregularities and prolongation of the QT segment of the electrocardiogram. It is 
estimated that about $50 \%$ of cases of pseudohypoparathyroidism have epileptic seizures.

The commonly accepted cardinal signs are due to increased myoneural irritability and consist of contraction of the facial muscles when the facial nerve is tapped over its course across the parotid gland in front of the masseter muscle (Chvostek's sign) and dorsal flexion and abduction of the foot when the peroneal nerve is tapped as it crosses the fibula (peroneal sign). In addition, the metacarpalphalangeal joints are flexed tetanically when a blood pressure cuff is inflated until it occludes the venous return from the forearm (Trousseau's sign). Hyperventilation during occlusion of the venous circulation to the arm accentuates the muscle spasm (von Bonsdorff's phenomenon).

The seizures that occur in pseudohypoparathyroidism due to hypocalcaemia are usually generalized but brief lapses of consciousness similar to petit mal epilepsy also occur. There is some evidence that seizures in patients suffering from coexistent focal epilepsy are increased by hypocalcaemia. Papilloedema is occasionally seen. The increased intracranial pressure in hypocalcaemia is believed to be due to a direct metabolic effect of hypocalcaemia (Sugar, 1953; Robinson, Kallberg, and Crowley, 1954).

In addition to the changes due to hypocalcaemia, there is a characteristic habitus in pseudohypoparathyroidism. This consists of short stature, stocky body build, round face, and shortening of the metacarpal and metatarsal bones due to early epiphyseal closure. The last abnormality of the bones of the hand results in a dimple, instead of a knuckle, at the base of the affected finger when the hand is clenched. Occasionally, subcutaneous ossification also occurs.

Pseudo-pseudohypoparathyroidism was described by Albright, Forbes, and Henneman (1952) and several subsequent cases have been reported. In this condition, the patient has the same habitus that is present in pseudohypoparathyroidism but the serum calcium and phosphorus levels are normal and tetany is absent. As far as we are aware, evidence has not been previously presented that this is probably a forme fruste of pseudohypoparathyroidism.

The classical E.E.G., clinical, radiological, and biochemical features that characterize these conditions are summarized in Table $I$.

\section{Clinical Observations}

Two patients will be presented: one suffers from pseudohypoparathyroidism, the other from pseudopseudohypoparathyroidism. These two patients are
TABLE J

CLINICAL FEATURES

\begin{tabular}{|c|c|c|c|}
\hline & $\begin{array}{l}\text { Hypopara- } \\
\text { thyroidism }\end{array}$ & $\begin{array}{l}\text { Pseudo- } \\
\text { hypopara- } \\
\text { thyroidism }\end{array}$ & $\begin{array}{l}\text { Pseudo-pseudo- } \\
\text { hypopara- } \\
\text { thyroidism }\end{array}$ \\
\hline $\begin{array}{l}\text { Mental deficiency } \\
\text { Tetany } \\
\text { Seizures } \\
\text { Intracranial calcification } \\
\text { Subcutaneous calcification } \\
\text { Hand deformities } \\
\text { Serum calcium } \\
\text { Serum phosphorus }\end{array}$ & $\begin{array}{l}\text { Common } \\
\text { Common } \\
40-50 \% \\
\text { Common } \\
\text { Absent } \\
\text { Absent } \\
\text { Low } \\
\text { Normal- }\end{array}$ & $\begin{array}{l}\text { Common } \\
\text { Common } \\
40-50 \% \\
\text { Common } \\
\text { Common } \\
\text { Common } \\
\text { Low } \\
\text { Normal- }\end{array}$ & $\begin{array}{l}\text { Common } \\
\text { Absent } \\
\text { Absent } \\
\text { Occasional } \\
\text { Rare } \\
\text { Common } \\
\text { Normal } \\
\text { Normal }\end{array}$ \\
\hline Urinary calcium & Normal- & $\begin{array}{l}\text { Normal- } \\
\text { low }\end{array}$ & Normal \\
\hline $\begin{array}{l}\text { Urinary phosphorus } \\
\text { Cataracts }\end{array}$ & Low & Low & $\begin{array}{l}\text { Normal } \\
\text { Rare }\end{array}$ \\
\hline
\end{tabular}

of unusual interest since they are members of the same family.

Case 1, Pseudohypoparathyroidism.-This is a 39-yearold white man who was admitted because of convulsions on January 16, 1957. He had had seizures and had been mentally retarded since childhood and had been supported at home by his family. He occupied his time by listening to the radio, conversing with the family, and helping with the housework. There would be periods lasting for trom several weeks to several months during which he would have few or no seizures; but, for several months before admission, the generalized seizures had been occurring more frequently. These "seizures" were described as both tetanic muscular contractions and generalized epileptic seizures. His vision had been poor since childhood, but he had been blind for approximately two years.

The family history is reviewed in Fig. 1 and it will be noted that his mother (Case 2) is known to have pseudo-o pseudohypoparathyroidism and we believe it probable?
that several other members of the family have pseudohypoparathyroidism or pseudo-pseudohypoparathyroidism.

On physical examination, the blood pressure was $120 / 90 \mathrm{~mm}$. $\mathrm{Hg}$ : pulse 92 per minute, and respirations were totally irregular. He was comatose except for brief episodes of grimacing at intervals of two to 10 minutes followed by carpal spasm, flexion of the lower extremities, and tetanic laryngeal spasm and apnoea which would be followed by five or six deep breaths and relaxation of the whole body. In addition, generalized seizures occurred. There were many recent and partly healed skin abrasions over the whole body and a flat, $10 \times 7 \mathrm{~cm}$., stony hard plaque in the subcutaneous tissue just inferior to the right scapula; this was freely moveable and was not tender. Both ears were unusually hard on palpation. Chvostek's sign was present. Bilateral mature cataracts were present and the patient was blind except for perception of light (Fig. 2A). The teeth were carious and widely separated and the dental enamel showed multiple ridges. Pyorrhoea was present. No knuckles were present at the fourth and fifth metacarpal-phalangeal joints on making a fist with either hand. The fourth and fifth fingers were also shortened (Fig. 2B). On both feet the second toe was longest with especially short third and 


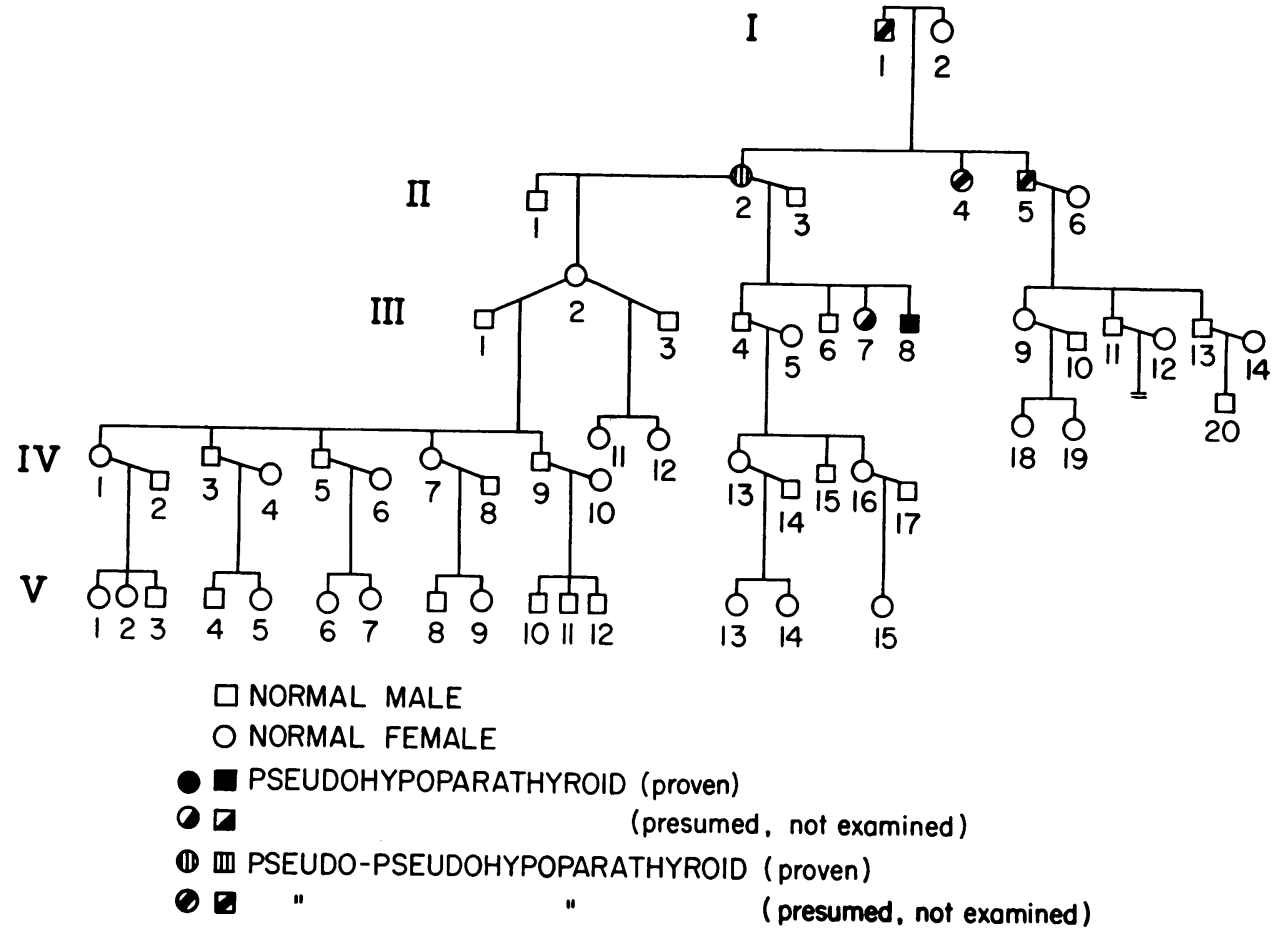

Fig. 1.-Family tree of the two cases described.

Sibship I, 1: This man was born in 1856 of Scottish and Irish parents who were reported to have been normal. He was very short and stocky but did not have poor vision. His hands were not abnormal. He did not have seizures. He died aged 70; the cause of death is unknown.

Sibship I, 2: This woman was born in 1858 of French parents and was normal and not related to her husband. An automobile struck and killed her at age 82 .

Sibship II, 2: This woman had proven pseudo-pseudohypoparathyroidism and is reported as Case 2.

Sibship II, 4: This woman is short, stocky, and 79 years of age. She was able to complete only the fourth grade at school and her hands are reported to be small and broad with two or three short fingers. She has never had seizures or poor vision suggesting cataracts. She is a recluse, does not communicate with the rest of her family and declined to be examined for this study. She never married.

Sibship II, 5: This man was born in 1883 and is described as having been $4 \mathrm{ft}$. 9-11 in. tall and of stocky body build. His hands were normal and he did not have poor vision or convulsions. He died at age 55 reportedly due to a gastric ulcer.

Sibship III, 4: This man was born in 1912 and is very short but is also thin and otherwise normal.

Sibship III, 6: This person died aged 7 from a proven case of meningitis. His development appeared normal and he was doing well at school.

Sibship III, 7: This girl died at age 18 months from convulsions. Nothing else is known about her except that she was very obese. She did not die at the same time as III, 6 did.

Sibship III, 8: This man has pseudohypoparathyroidism and is reported as Case 1.

The remainder of the family, as shown above, is reported to be normal. We are greatly indebted to Dr. James V. Neal and Mrs. Ruth T. Davidson of the Department of Human Genetics of the University of Michigan for this pedigree.

fourth toes. There was bilateral pes cavus. Total height was $149 \mathrm{~cm}$.; vertex-symphysis height was $73 \mathrm{~cm}$., and symphysis-floor was $76 \mathrm{~cm}$. Genitalia were normal except that the right testicle was soft and smaller than the left. The remainder of the medical examination was normal.

Laboratory studies on admission showed the haemoglobin to be $11.0 \mathrm{~g}$. with a normal total and differential white blood cell count. The fasting blood sugar was $76 \mathrm{mg} . \%$, blood urea nitrogen $15 \mathrm{mg} . \%$, serum protein 7.1 g. $\%$ (4.3 g. $\%$ and 2.8 g. $\%$ globulin). The serum calcium was $4 \cdot 2 \mathrm{mg} . \%$ (normal $9 \cdot 0-11 \cdot 0$ ), phosphorus $7.6 \mathrm{mg} . \%$ (normal $3 \cdot 2-4 \cdot 3$ ), and alkaline phosphatase was $4 \cdot 5$ Bodansky units (normal).
Administration of parathyroid extract produced no phosphaturia, elevation of the serum calcium, or reduction of the serum phosphorus levels.

Radiographs of both hands showed shortening of the fourth metacarpal (Fig. 2C). Radiographs of the skull showed a normal mineral content of the cranial vault, but there was irregular bilateral calcification of the basal ganglia. The vertebral column showed slight demineralization with minor concave deformities of the vertebral bodies and slight scoliosis to the right at the level of the fourth thoracic vertebra. There was slight irregularity of the fourth, fifth, and sixth ribs posteriorly on the right. The pleura was calcified. There was a large calcified plaque lying in the soft tissues of the right 

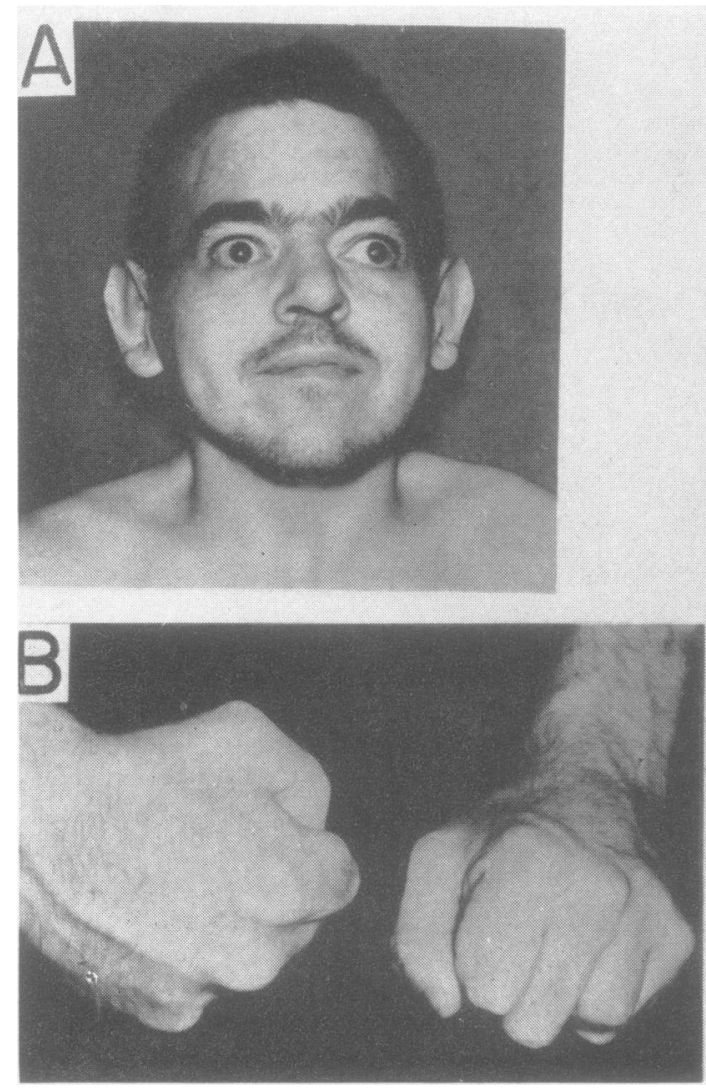

FIG. 2.-Case 1: A, Characteristic facies; B, hands showing shortened knuckle at fourth metacarpalphalangeal joint;

$\mathrm{C}$, radiograph of right hand showing shortened fourth metacarpal.

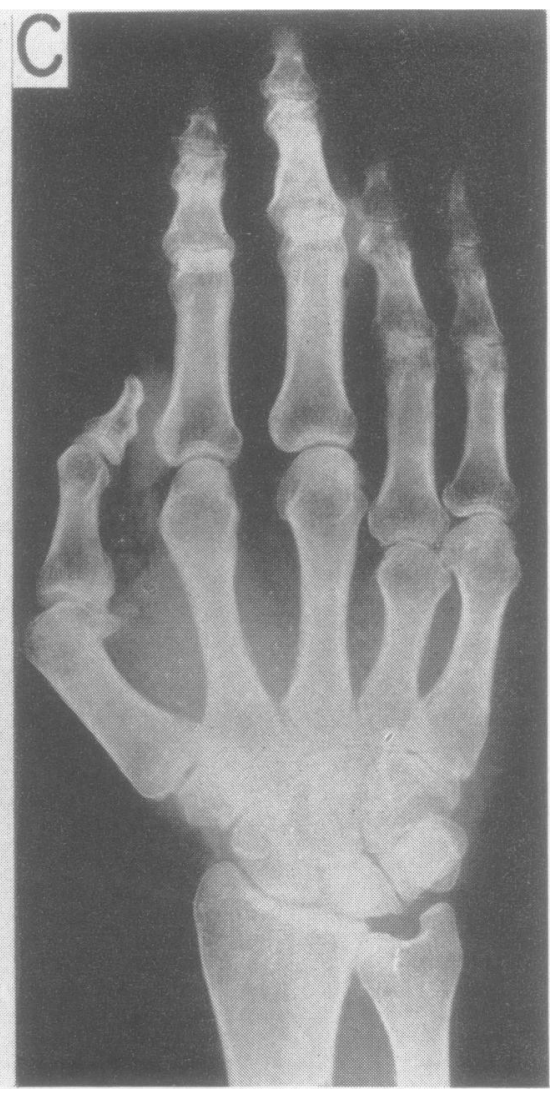

posterior chest wall. Slight demineralization of the lumbar spine and pelvis was present and the iliac wings were noted to be small compared with the rest of the pelvis. Myositis ossificans was present in the area of the left hip joint. Both mandibles were almost edentulous; the remaining teeth were hypoplastic with shortened roots. Intravenous pyelography was normal. The E.E.G. is illustrated in Fig. 3. It was diffusely abnormal with a predominant rhythm of low-voltage fast activity with long runs of bilaterally symmetrical 5-6 per second theta activity. During the 50-minute test, there were nine bursts consisting of multiple spikes occurring at a frequency of four to five per second and of multifocal or diffuse origin.

He was treated with a low phosphorus diet, probenecid, and large doses of vitamin $\mathrm{D}$ and dihydrotachysterol (AT-10) without change in his blood chemistry. The addition of aluminium hydroxide gel reduced the urinary phosphorus but the serum levels remained unchanged. In spite of this therapy, he had continued episodes of tetany followed by generalized seizures. The seizures and tetany responded well to intravenous administration of calcium gluconate. Both cataracts were removed. The mass below the right scapula was removed and proved to be a calcific plaque of fibrous tissue with ectopic bone formation. A renal biopsy was normal.

Case 2, Pseudo-pseudohypoparathyroidism.-A 79year-old housewife, the mother of Case 1, was brought to Detroit Receiving Hospital in heart failure. She had suffered from exertional paroxysmal nocturnal dyspnoea, orthopnoea, and pedal oedema for six weeks before admission. Her first episode of heart failure had occurred in 1952 when it had been compensated with digitalis which she had taken until she discontinued her medication several months before admission.

She had always been short of stature and had been mentally retarded since birth. She had noticed failing vision for 10 years but, with her glasses, was able to read a newspaper.

Her family history is of unusual interest and is illustrated in Fig. 1. It will be noted from the pedigree that her son is Case 1.

The physical examination disclosed a blood pressure of $118 / 70 \mathrm{~mm}$. $\mathrm{Hg}$, a pulse of 100 per minute which was irregular. She had bilateral lenticular opacities. The 

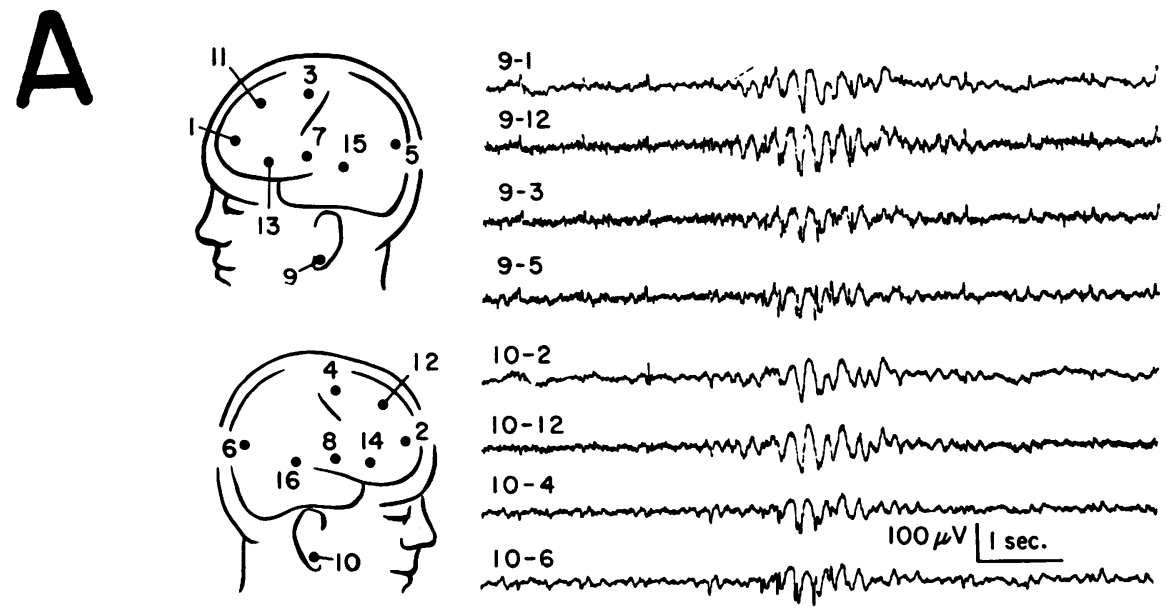
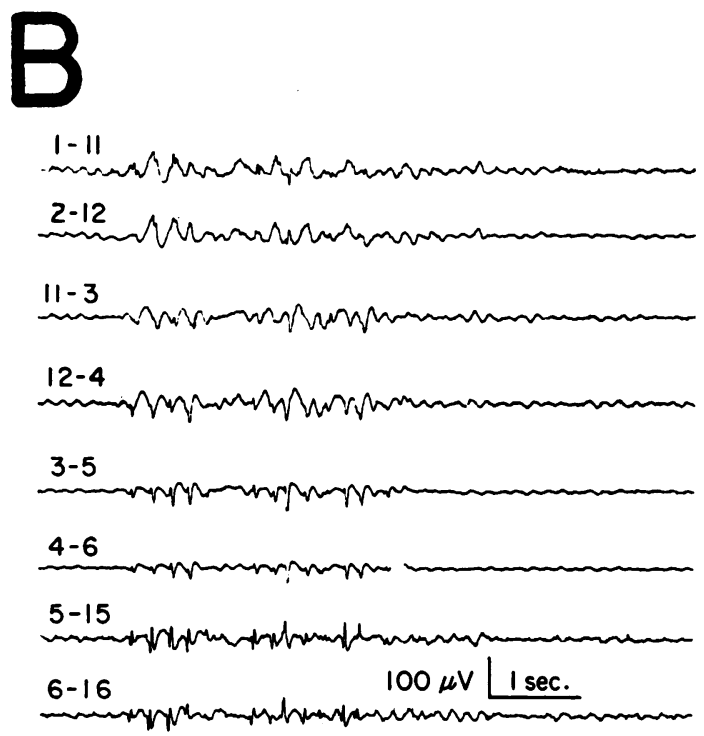

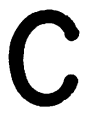

$9-13$

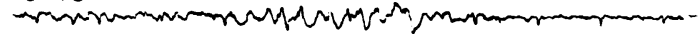

13-11

$11-12$

$12-13$

12-13

$14-10$

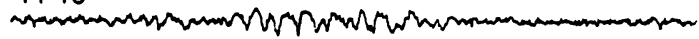

$10-9$

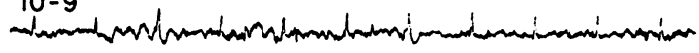

11-9

12-10

FIG. 3.-(A), (B), and (C) are samples of the E.E.G. record from Case 1 during minor seizures simulating petit mal.

A, Atypical spike-wave complexes in occipital leads; B, diffuse high voltage slowing in bursts with atypical occipital spike-wave complexes; C, occipital bursts of spike activity and diffuse slow waves in bursts.

right submaxillary salivary gland was enlarged and firm. No knuckles were noted at the third, fourth, and fifth metacarpalphalangeal joints when she made a fist with either hand. Bilateral fine basilar rales were heard on auscultation. The heart was enlarged to the left and the rhythm was totally irregular but no murmurs were heard. There was pitting oedema with stasis dermatitis and cellulitis of both lower extremities. The rest of the physical examination was normal.

The venous pressure was $295 \mathrm{~mm} . \mathrm{H}_{2} \mathrm{O}$ increasing to $360 \mathrm{~mm}$. on compression of the right upper quadrant. The arm-to-tongue circulation time was 18 seconds. Her height was $145 \mathrm{~cm}$.

The hemoglobin was $10 \cdot 2 \mathrm{~g} . \%$, total white blood cell count was 6,500 per c. $\mathrm{mm}$. with a normal differential count. The urine analysis was normal and the blood urea nitrogen was $36 \mathrm{mg} . \%$. The serum protein was $7 \cdot 5 \%(4.8 \mathrm{~g}$. albumin and $2 \cdot 7 \mathrm{gr}$. globulin). The serum calcium was $10 \mathrm{mg} . \%$, serum phosphorus $2.7 \mathrm{mg} . \%$, and alkaline phosphatase 4.7 Bodansky units.

Radiological examination of the hands and feet showed shortening of the metacarpals and metatarsals (Fig. 4). The ears showed soft tissue calcification. There was generalized bony demineralization and osteoarthritis of the spine.

The E.E.G. showed well-modulated alpha and beta activity with no localized abnormality. There were frequent bursts of bilateral slowing in the theta and delta 


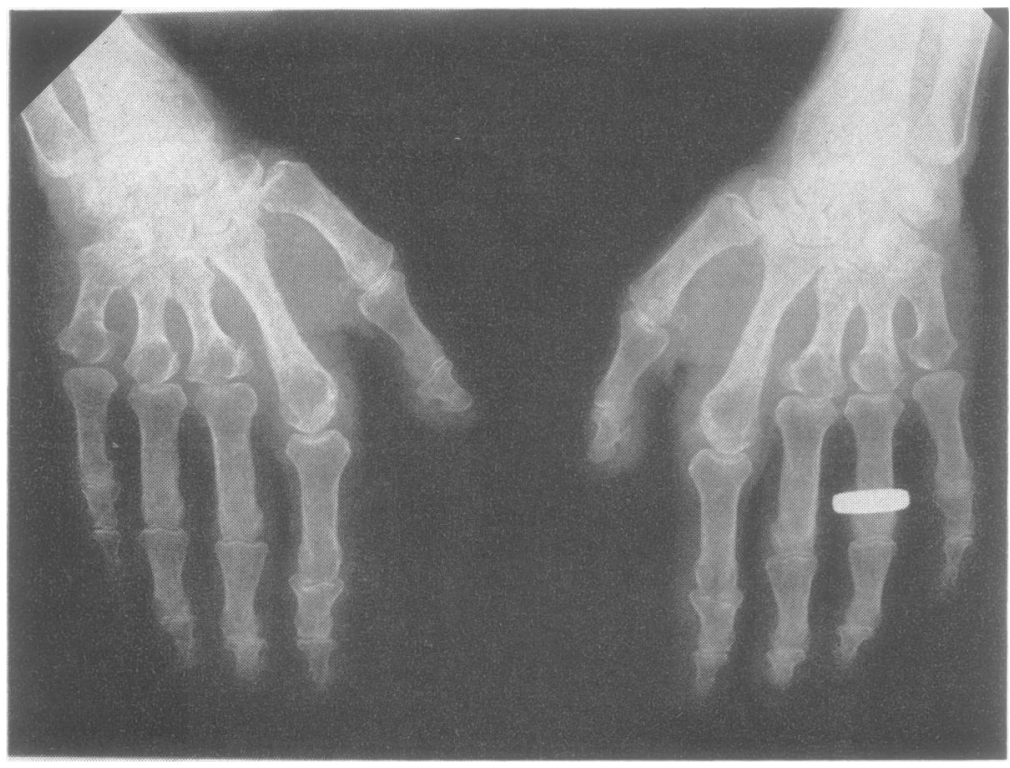

Fig 4.-Case 2: Radiograph of both hands showing shortened third. fourth and fifth metacarpals.

range with bifrontal preponderance. No significant changes were produced by hyperventilation.

Treatment with digitalis was reinstituted and the signs of cardiac failure subsided and, after 30 days, she was discharged.

\section{Treatment}

The treatment of pseudohypoparathyroidism is essentially the same as for true hypoparathyroidism, except that parathyroid hormone is not of benefit. The aim of treatment is correction of the abnormal levels of serum calcium and phosphorus. When seizures and tetany are present, this should be accomplished rapidly and may be done by the intravenous infusion of calcium gluconate or calcium chloride supplemented by AT-10 for the first few days of therapy.

For long-term therapy, a low-phosphorus diet may be of value, although, in the case reported above, serum phosphorus was not lowered by such a regimen. Since the restriction of phosphorus-containing foods makes the diet somewhat unpalatable, the alternative of using aluminium hydroxide gel is suggested. By giving 15 to $30 \mathrm{ml}$. of this compound with each meal, it is possible to reduce the urinary phosphorus output to a few hundred milligrams per day. Some cases of pseudohypoparathyroidism have been reported to show restoration of serum calcium and phosphorus levels toward normal with AT-10 or vitamin D together with an increased intake of calcium, although in the above patient, this was not so. If a measure is found to increase serum calcium, it should be employed even in asymptomatic patients, because of the frequency with which cataracts develop.

\section{Discussion}

We have presented a family in which one member suffers from pseudo-pseudohypoparathyroidism and her son from pseudohypoparathyroidism (Fig. 1). Other members of this family also exhibit certain features suggestive of these conditions although they have not been examined by us.

Previous reports have shown that pseudohypoparathyroidism and pseudo-pseudohypoparathyroidism may occur separately in different families (ten Bosch, 1959; Seringe and Tomiewicz, 1957) and recently ten Bosch has reported four patients with gonadal dysgenesis and pseudo-pseudohypoparathyroidism.

Only one family, other than the one we have described, has been reported in which pseudopseudohypoparathyroidism and pseudohypoparathyroidism occurred in succeeding generations (Selye, 1949). To the best of our knowledge, the possible genetic relationship of these two disorders has not been sufficiently emphasized. A review of all case reports of pseudohypoparathyroidism reveals that the association of these two conditions has been considered by others. For example, of the 25 cases of pseudohypoparathyroidism reported before 1955 and reviewed by Frame and Carter (1955), 11 cases had relatives with formes frustes of the classical picture of pseudo-pseudohypoparathyroidism. In this review there were 14 relatives 
so affected and 11 of these were female. In our own pedigree we suspect that there were two individuals in the same generation who suffered from pseudohypoparathyroidism: Case 1 had an obese sister who died at 18 months of age. Furthermore, in the preceding generation, there are several individuals, on the maternal side, who appear to be formes frustes of the clinical picture of pseudo-pseudohypoparathyroidism.

This familial association of pseudohypoparathyroidism and pseudo-pseudohypoparathyroidism in a significant number of reported cases, and in at least two of the members of the family reported here, suggests that these two conditions are genetically related. For example, it is possible that the defect in renal tubular function is the result of one genetic defect and that the abnormalities of habitus and mentation may be due to one or more associated genetic traits which need to be present for appearance of the whole clinical picture of pseudohypoparathyroidism. Another possible explanation for the observed relationship is that the two conditions are due to a single abnormal gene which is incompletely penetrant and is expressed in pseudopseudohypoparathyroidism. If one of these explanations is true, it might be expected that some patients with apparent spontaneous hypoparathyroidism, but who have been refractory to injected parathyroid extract, might represent the other end of this disease spectrum. Their genetic defect then would be expressed only in such a way that we can measure it as altered calcium and phosphorus metabolism. The difficulty with trying to prove such a theory is that, in the past, parathyroid extract has varied so greatly in its ability to produce phosphaturia in normal patients and those with surgically induced hypoparathyroidism that it has been difficult to assess the exact significance of poor response to injected parathyroid hormone. With more reliable extracts of parathyroid tissue available, it might be wise to perform the Ellsworth-Howard test on patients who, from all outward appearances, are true cases of hypoparathyroidism, especially if they respond poorly to therapy with vitamin $\mathrm{D}$ or AT-10.

Another possible viewpoint is that all the manifestations of pseudo-hypoparathyroidism are due to a single metabolic defect, namely, the excessive reabsorption of phosphate by the renal tubules. The skeletal changes might then be attributable to disordered mineral metabolism early in life, perhaps in utero. Furthermore, it might be postulated that, in pseudo-pseudohypoparathyroidism, the tubular defect was present in early life and disappeared after the typical skeletal changes had already been produced. This possibility seems unlikely, however, because of certain selective changes in bones, e.g., shortened metacarpals, and the characteristic facies would require further explanation. Also, children born of hypoparathyroid mothers and animals born of hypoparathyroid mothers or animals made hypoparathyroid by surgery shortly after birth fail to show these characteristic changes of pseudohypoparathyroidism.

True hypoparathyroidism and pseudohypoparathyroidism seem to be associated with similar E.E.G. abnormalities. These consist of paucity of alpha rhythm, increased fast activity, simple spike activity, and slow waves of 6-7 per second frequency.

These conditions are of special interest to the neurologist because patients with hypoparathyroidism or pseudohypoparathyroidism present with symptoms of tetany, seizures, mental retardation, papilloedema, intracranial calcification, and abnormalities of the E.E.G. If these conditions are not considered, the diagnosis of brain tumour, idiopathic epilepsy, and cerebral palsy may be made. In the diagnostic evaluation of all patients with seizures, hypocalcaemia should be excluded.

\section{Summary and Conclusion}

The clinical features of pseudohypoparathyroidism and pseudo-pseudohypoparathyroidism have been reviewed with particular emphasis on the neurological and E.E.G. abnormalities.

The association of pseudohypoparathyroidism and pseudo-pseudohypoparathyroidism have been reported in one family and the pedigree of this family suggests that other members of the family were also affected. It is concluded that these two conditions represent different manifestations of a genetically determined spectrum of abnormalities of habitus and renal function.

\section{REFERENCES}

Albright, F., Burnett, C. H., Smith, P. H., and Parson, W. (1942). Endocrinology, 30, 922

Forbes, A. P., and Henneman, P. H. (1952). Trans. Ass. Amer. Phycns., 65, 337.

Carnes, W. H. (1950). Amer. J. Path., 26, 736.

Ellsworth, R., and Howard, J. E. (1934). Bull. Johns Hopk. Hosp., $55,296$.

Frame, B., and Carter, S. (1955). Neurology, 5, 297.

Harell-Steinberg, A., Ziprkowski, L., Haim, S., Gafni, J., and Levin, M. (1957). J. clin. Endocr., 17, 1099.

Milne, M. D. (1951). Clin. Sci., 10, 47i.

Robinson, K. C., Kallberg, M. H., and Crowley, M. F. (1954). Brit. Robinson, K. C., Kallbers.

Selye, Hed. J., 2, 1203. Endocrinilogica, Montreal, p. 569.

Seringe, P., and Tomkiewicz, S. (1957). Sem. Hop. Paris, 33, 1092P. Quoted by ten Bosch.

Stewart, G. S., and Bowen, H. F. (1951). Endocrinology, 48, 568.

Sugar, O. (1953). A.M.A. Arch. Neurol. Psychiat., 70, 86.

ten Bosch, J. J. van der W. (1959). Lancet, 1, 69. 